\title{
Miniaturized CPW-Fed Triband Antenna with Asymmetric Ring for WLAN/WiMAX Applications
}

\author{
Shanshan Huang, Jun Li, and Jianzhong Zhao \\ Ministerial Key Laboratory of JGMT, Nanjing University of Science and Technology, Nanjing 210094, China \\ Correspondence should be addressed to Jun Li; lijun_njust@163.com
}

Received 9 June 2014; Revised 23 September 2014; Accepted 1 October 2014; Published 16 October 2014

Academic Editor: Mohamed El-Tanany

Copyright (C) 2014 Shanshan Huang et al. This is an open access article distributed under the Creative Commons Attribution License, which permits unrestricted use, distribution, and reproduction in any medium, provided the original work is properly cited.

A compact CPW-fed triband slot antenna for WLAN/WiMAX applications is proposed. The proposed antenna is formed by an asymmetric ring, an inverted L-strip, and a straight strip. By employing these structures, the antenna can generate three operation bands with compact size and simple structure. The measured and simulated results show the presented antenna has impedance bandwidths of $100 \mathrm{MHz}(2.39-2.49 \mathrm{GHz}), 360 \mathrm{MHz}(3.36-3.72 \mathrm{GHz})$, and $760 \mathrm{MHz}(5.13-5.89 \mathrm{GHz})$, which covers both WLAN in the $2.4 / 5.2 \mathrm{GHz}$ bands and WiMAX in the $3.5 / 5.5 \mathrm{GHz}$ bands. The antenna is successfully simulated and measured, showing triple bands can be obtained by using three different radiators and also indicating that the proposed antenna is suitable for the WiMAX/WLAN applications.

\section{Introduction}

In recent years, with the rapid development of WLAN/ WiMAX systems, the demand for antennas with small size, low cost, multifrequency operation capabilities, and high efficiency has increased. In order to meet WLAN/WiMAX applications, a broadband antenna or a multiband antenna covering all the WLAN/WiMAX operation bands is a candidate. However the multiband antenna is more attractive than broadband antenna, because the broadband antennas contain dispensable bands in WLAN/WiMAX system. Many multiband antennas have been proposed for WLAN or WiMAX applications such as [1-15]. For example, a CPW-fed antenna [1] composed of $U$-shaped and triangular radiating elements can generate two bands to meet the requirements for WLAN/WiMAX systems. The proposed antenna in [2] is coupled-fed through L-shaped and E-shaped resonant elements to obtain two operation bands. Although the antennas in $[1-4]$ can yield two widebands for WLAN or WiMAX operations, there are still some drawbacks to be improved. Triband antenna only for WiMAX application is obtained by a coupled dual-U-shaped radiator in [5]. Ultrawideband (UWB) antenna with triple band-notched characteristics is presented in [6]. In [9] a microstrip-fed monopole antenna with a fork-shaped strip is proposed to meet WLAN and WiMAX applications. The antennas in [5-11] have some disadvantages. For instance, designs procedures of the proposed antennas in [6-8] are complex, antenna presented in [6] cannot cover the frequency band $2.4-2.48-\mathrm{GHz}$, and antenna in [8] is only capable of WLAN operation which limits the numbers of operation modes in portable equipment. The dimensions of antennas in $[9,10]$ are with large size of 34.5 $\times 18 \times 1 \mathrm{~mm}^{3}$ [9], $30 \times 20 \times 0.8 \mathrm{~mm}^{3}$ [10], and $30 \times 18 \times$ $1.6 \mathrm{~mm}^{3}$ [11] which may limit their integration with future miniaturized wireless communication systems.

In this paper, we present the design, fabrication, and characterization of a novel and compact CPW-fed triband antenna. The proposed antenna consists of an asymmetric ring, an inverted L-strip, and a straight strip in order to drive three different resonant modes. According to the sizes of these three elements, three distinct bands can be obtained, respectively. The dimension of the proposed antenna is only $22 \times 20 \times 1.6 \mathrm{~mm}^{3}$. Measured results demonstrate that the antenna can effectively cover three impedance bandwidths of $100 \mathrm{MHz}(2.39-2.49 \mathrm{GHz}), 360 \mathrm{MHz}$ (3.36$3.72 \mathrm{GHz})$, and $760 \mathrm{MHz}(5.13-5.89 \mathrm{GHz})$, which is suitable 


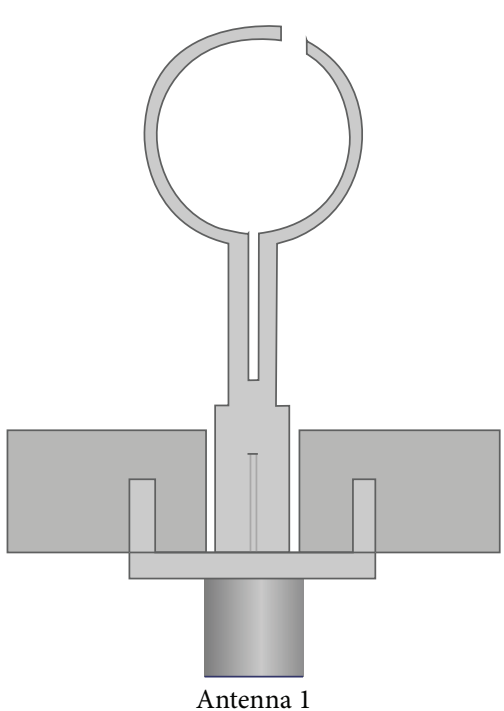

(a)

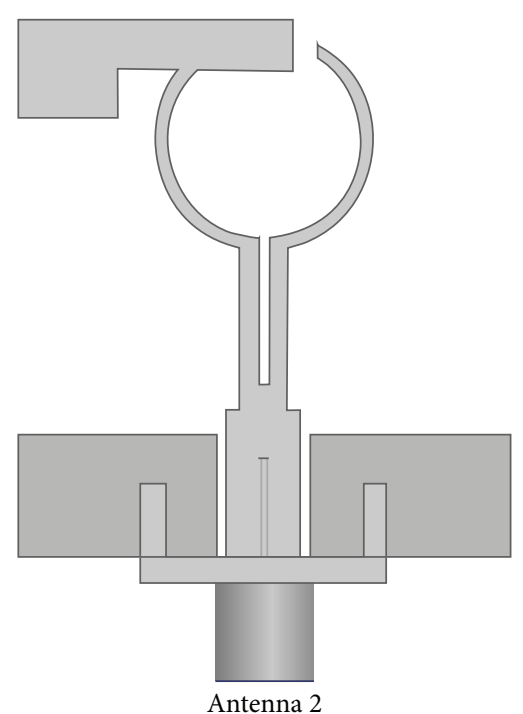

(b)

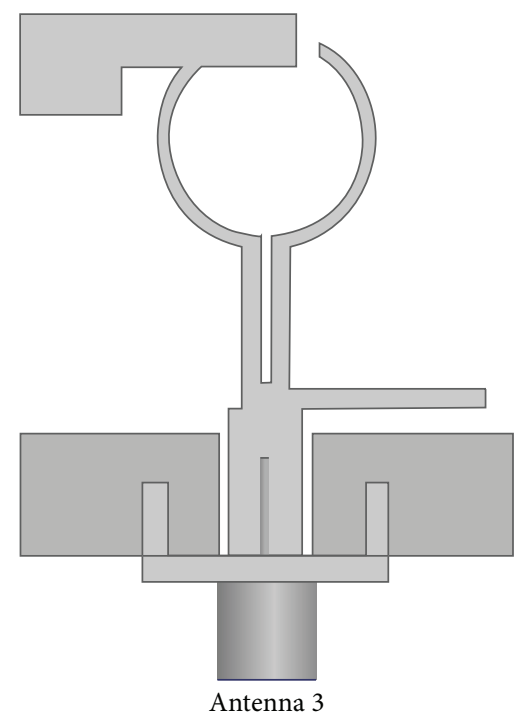

(c)

Figure 1: Geometry of Antenna 1, Antenna 2, and Antenna 3.

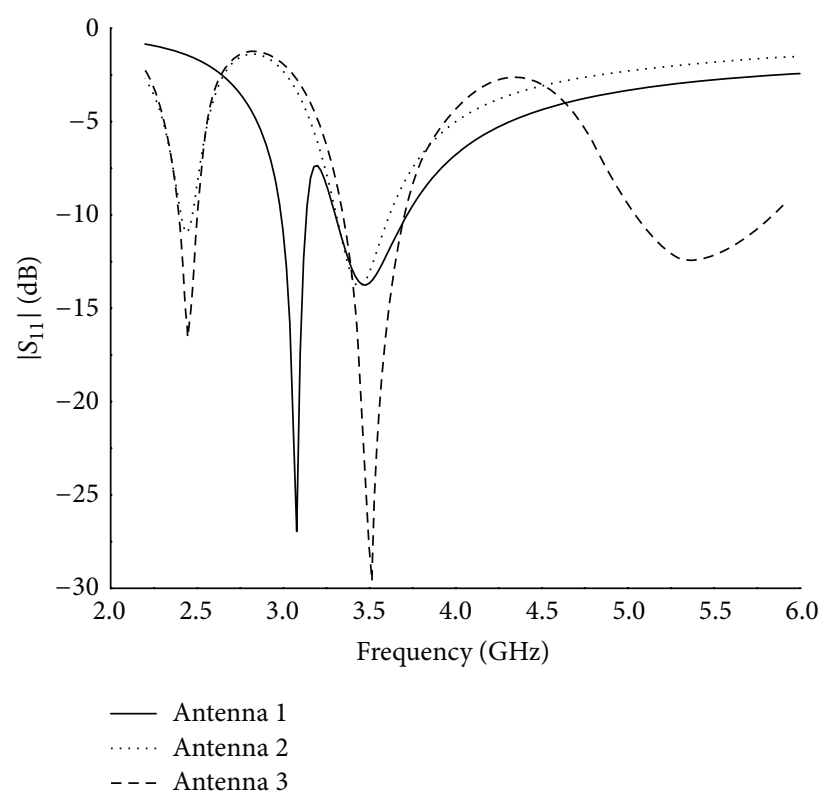

Figure 2: Simulated $\left|S_{11}\right|$ of Antenna 1, Antenna 2, and Antenna 3.

for $2.4 / 5.2 / 5.8 \mathrm{GHz}$ WLAN bands and 3.5/5.5 GHz WiMAX bands. The simulation works of the proposed antenna are carried out by using a full-wave electromagnetic (EM) simulator ANSYS HFSS V13.

\section{Design Procedure}

To meet the three operation bands for WLAN/WiMAX applications, the design procedure of the proposed triband antenna is illustrated in Figure 1. First, an asymmetric ring is designed (Antenna 1), which is composed of two resonant elements. Then, an inverted L-strip is attached to the asymmetric ring as shown in Figure 1, Antenna 2. The inverted L-strip and the left side of the asymmetric ring can yield the lower band. Finally, a straight strip is added to Antenna 2, as depicted in Figure 1, Antenna 3, to generate the third band. Thus, the proposed triband antenna (Antenna 3) for WLAN/WiMAX communication systems is designed. Figure 2 shows the simulated return losses of Antenna 1, Antenna 2, and Antenna 3.

The configuration of the proposed triband antenna (i.e., Antenna 3 in Figure 1) is exhibited in Figure 3(a), and the photograph of the fabricated prototype antenna is shown in Figure 3(b). The proposed antenna is designed 


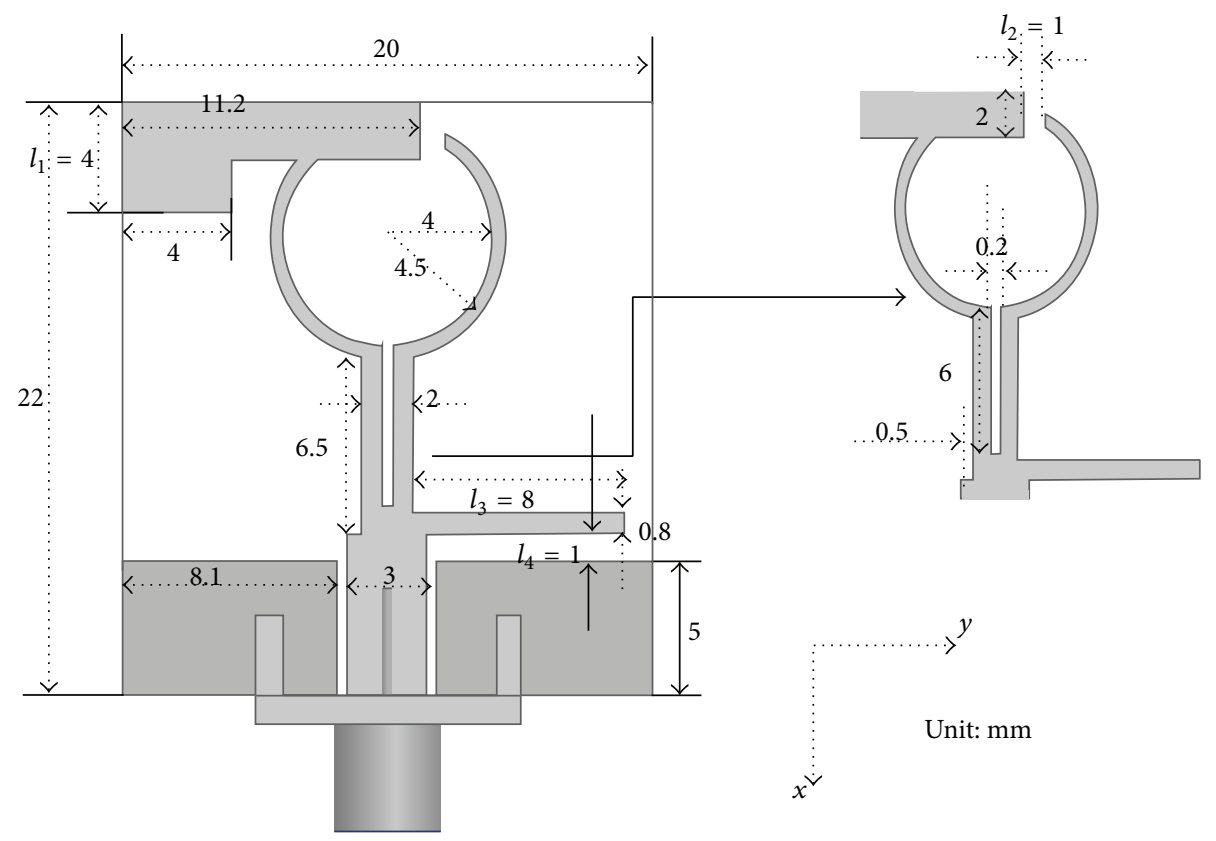

(a)

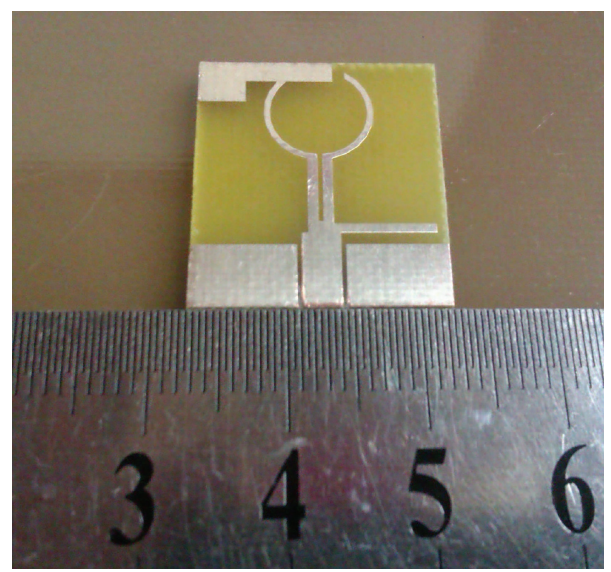

(b)

Figure 3: (a) Layout of the proposed triband antenna. (b) Photograph of the fabricated prototype antenna.

TABLE 1: Comparison of the proposed triband antenna with some reported works.

\begin{tabular}{lccc}
\hline References & Size $\left(\mathrm{mm}^{2}\right)$ & Applications & Bandwidths $(\mathrm{GHz})$ \\
\hline$[5]$ & $27 \times 39.5$ & WiMAX & $2.42-2.7 / 3.46-4.46 / 5.72-5.85$ \\
{$[9]$} & $34.5 \times 18$ & WLAN/WiMAX & $2.35-2.49 / 3.27-3.8 / 4.65-5.89$ \\
{$[10]$} & $30 \times 20$ & WLAN/WiMAX & $2.4-2.74 / 3.41-3.75 / 5.24-5.88$ \\
{$[11]$} & $30 \times 18$ & WLAN/WiMAX & $2.39-2.69 / 3.38-3.73 / 5-5.99$ \\
{$[12]$} & $40 \times 40$ & WLAN/WiMAX & $2.28-2.58 / 3.38-3.66 / 5.07-5.86$ \\
{$[13]$} & $30 \times 40$ & WLAN/WiMAX & $2-2.89 / 3.18-3.95 / 4.7-5.95$ \\
{$[14]$} & $40 \times 40$ & WLAN/WiMAX & $2.28-3.23 / 3.28-3.94 / 5.05-6.17$ \\
{$[15]$} & $42 \times 25$ & WLAN/WiMAX & $2.37-2.72 / 3.39-4.07 / 4.92-6$ \\
This work & $22 \times 20$ & WLAN/WiMAX & $2.39-2.49 / 3.36-3.72 / 5.13-5.89$ \\
\hline
\end{tabular}




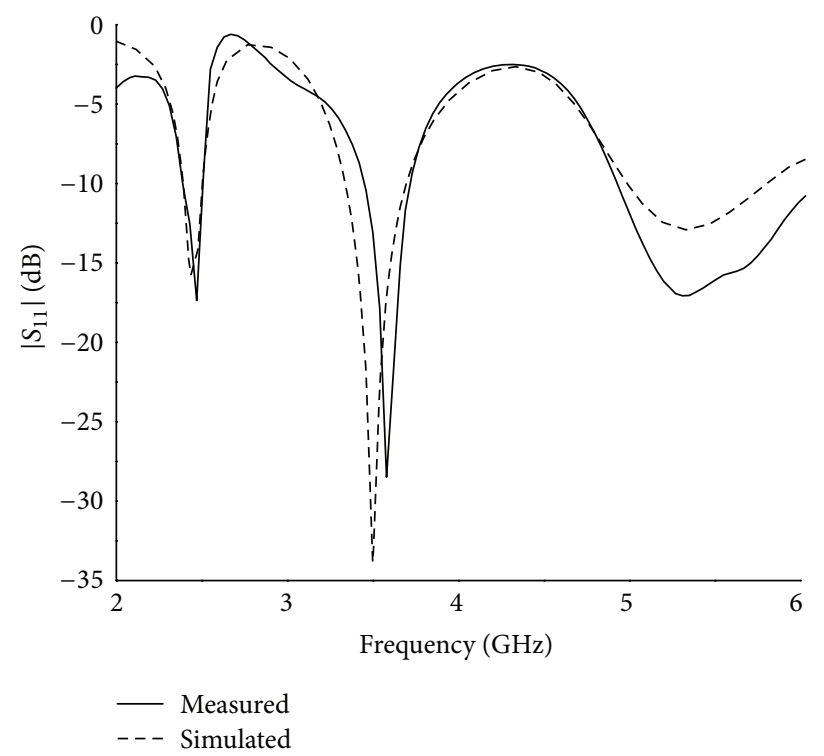

FIgURE 4: Simulated and measured return loss of the proposed antenna.

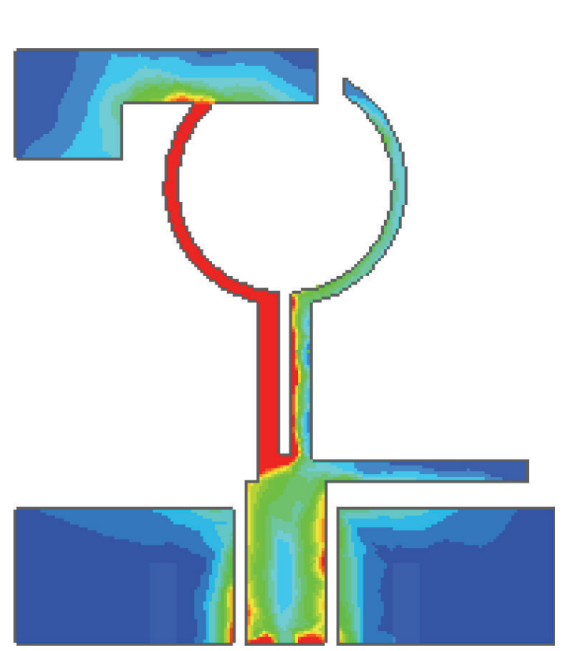

(a)

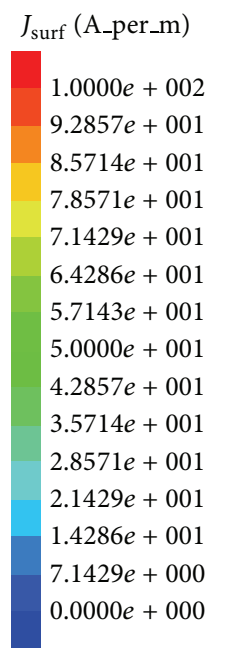

$1.0000 e+002$
$9.2857 e+001$
$8.5714 e+001$
$7.8571 e+001$
$7.1429 e+001$
$6.4286 e+001$
$5.7143 e+001$
$5.0000 e+001$
$4.2857 e+001$
$3.5714 e+001$
$2.8571 e+001$
$2.1429 e+001$
$1.4286 e+001$
$7.1429 e+000$
$0.0000 e+000$

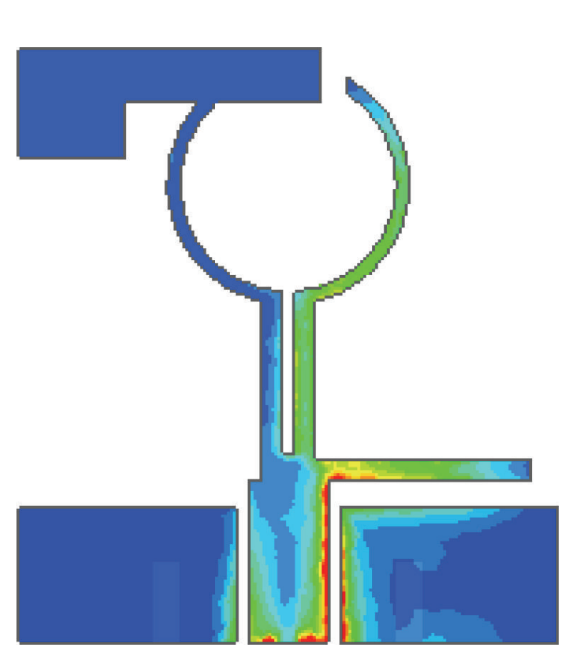

(b)

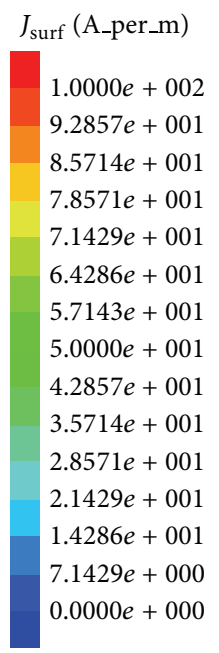

$J_{\text {surf }}($ A_per_m)

$1.0000 e+002$

$9.2857 e+001$

$8.5714 e+001$

$7.8571 e+001$

$7.1429 e+001$

$6.4286 e+001$

$5.7143 e+001$

$5.0000 e+001$

$4.2857 e+001$

$3.5714 e+001$

$2.8571 e+001$

$2.1429 e+001$

$1.4286 e+001$

$7.1429 e+000$

$0.0000 e+000$

(c)

FIGURE 5: Surface current distributions of proposed antenna at (a) 2.4, (b) 3.5, and (c) $5.5 \mathrm{GHz}$. 


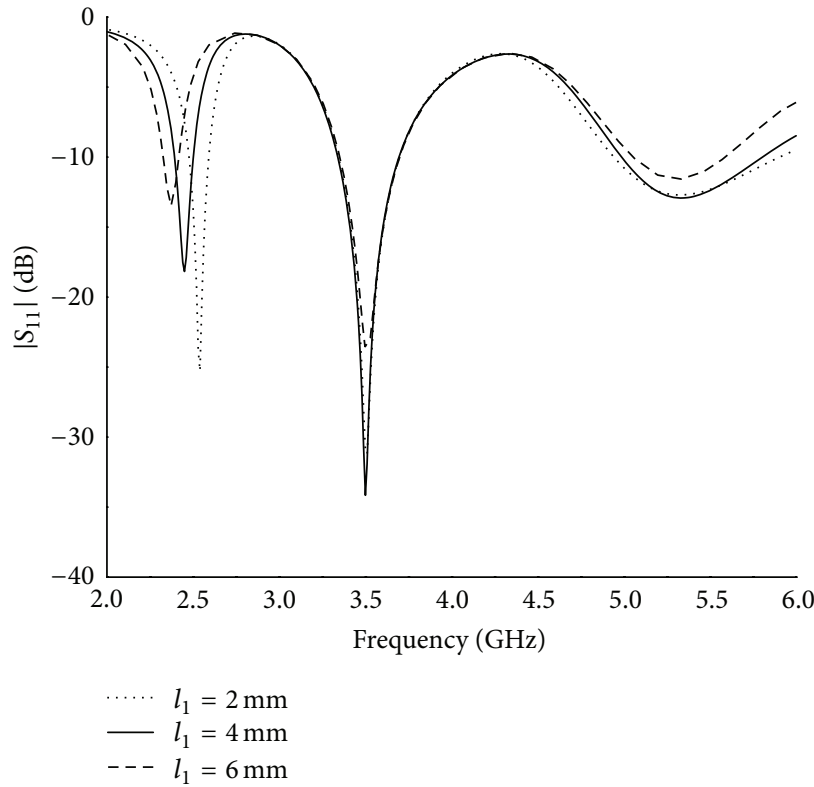

(a)

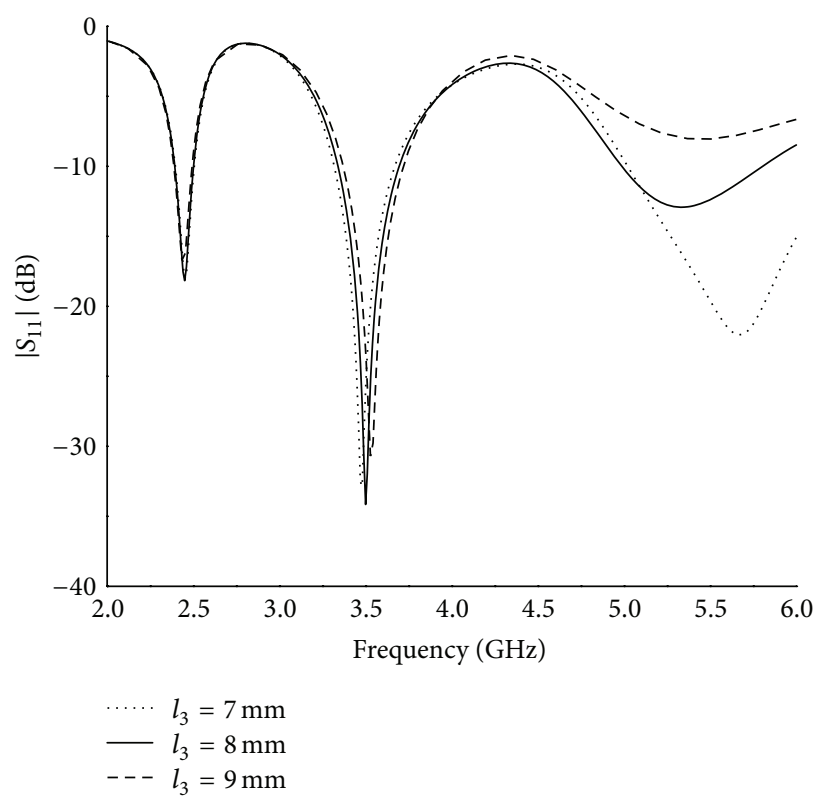

(c)

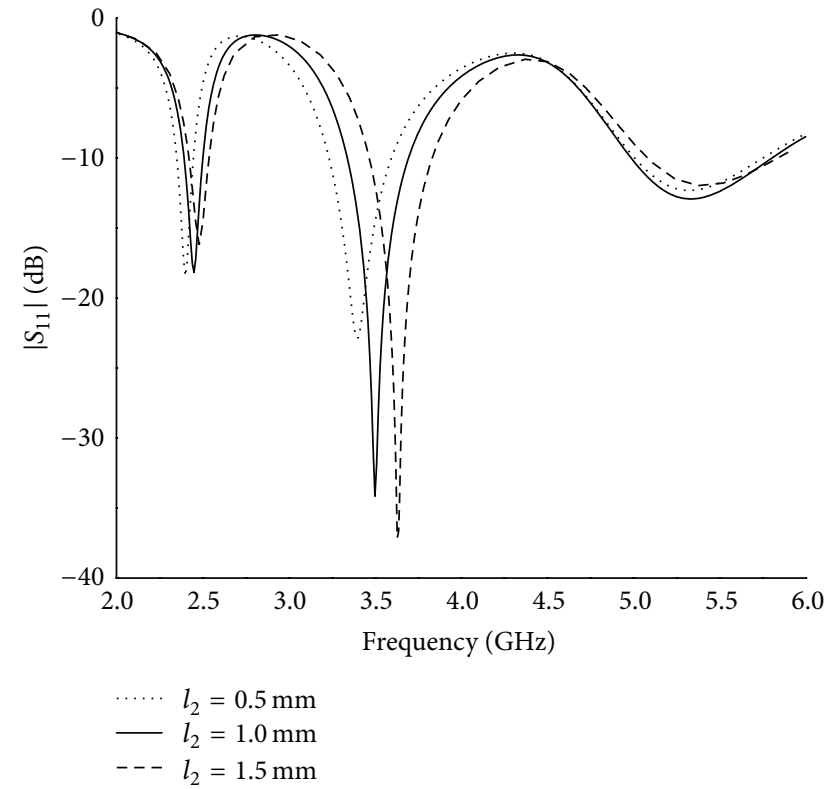

(b)

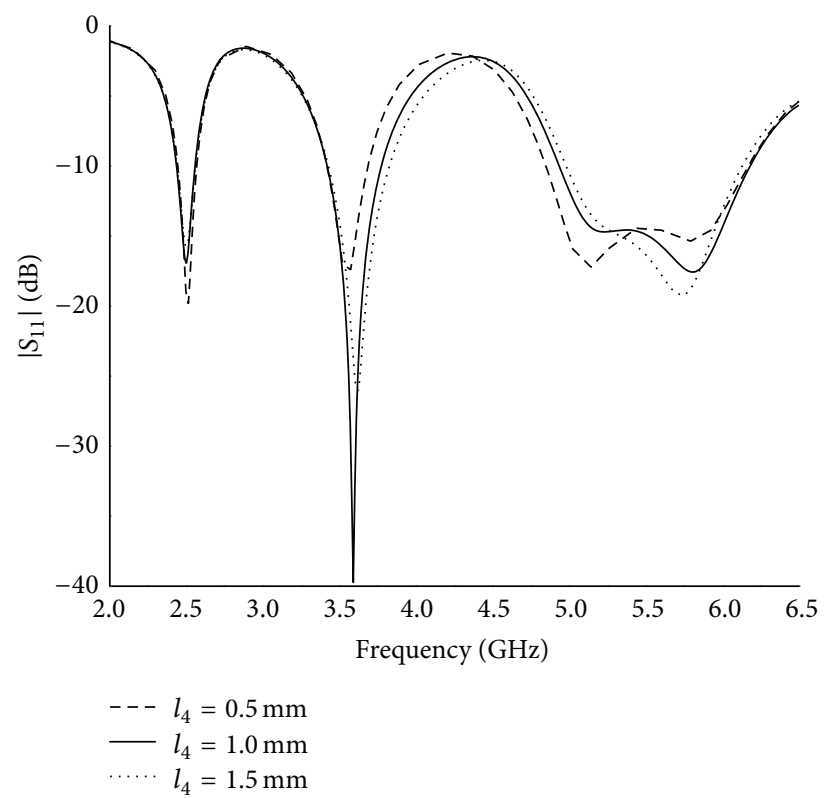

(d)

FIgURE 6: Simulated reflection coefficients of the triband antenna with varied(a) $l_{1}$, (b) $l_{2}$, (c) $l_{3}$, and (d) $l_{4}$.

and fabricated on a low-cost single-layer FR-4 substrate with a relative permittivity of 4.4 and a thickness of $1.6 \mathrm{~mm}$. The overall size of the proposed antenna occupies only $22 \times 20 \mathrm{~mm}^{2}$ which is much smaller than the antennas exhibited in [9-15]. The width of the $50-\Omega \mathrm{CPW}$-fed line is $3.0 \mathrm{~mm}$ and the gap distance between the $50-\Omega$ $\mathrm{CPW}$-fed line and the coplanar ground plane is $0.4 \mathrm{~mm}$. The length of each resonant element $(l)$ is close to a quarter of the guided wavelength $\left(\lambda_{g}\right)$ calculated at the desired resonant frequencies and $\lambda_{g}$ is obtain according to

$$
\begin{aligned}
\lambda_{g} & =\frac{c}{\sqrt{\varepsilon_{\mathrm{eff}}} f} \\
\varepsilon_{\mathrm{eff}} & \approx \frac{\left(\varepsilon_{r}+1\right)}{2} \\
l & =\frac{\lambda_{g}}{4},
\end{aligned}
$$



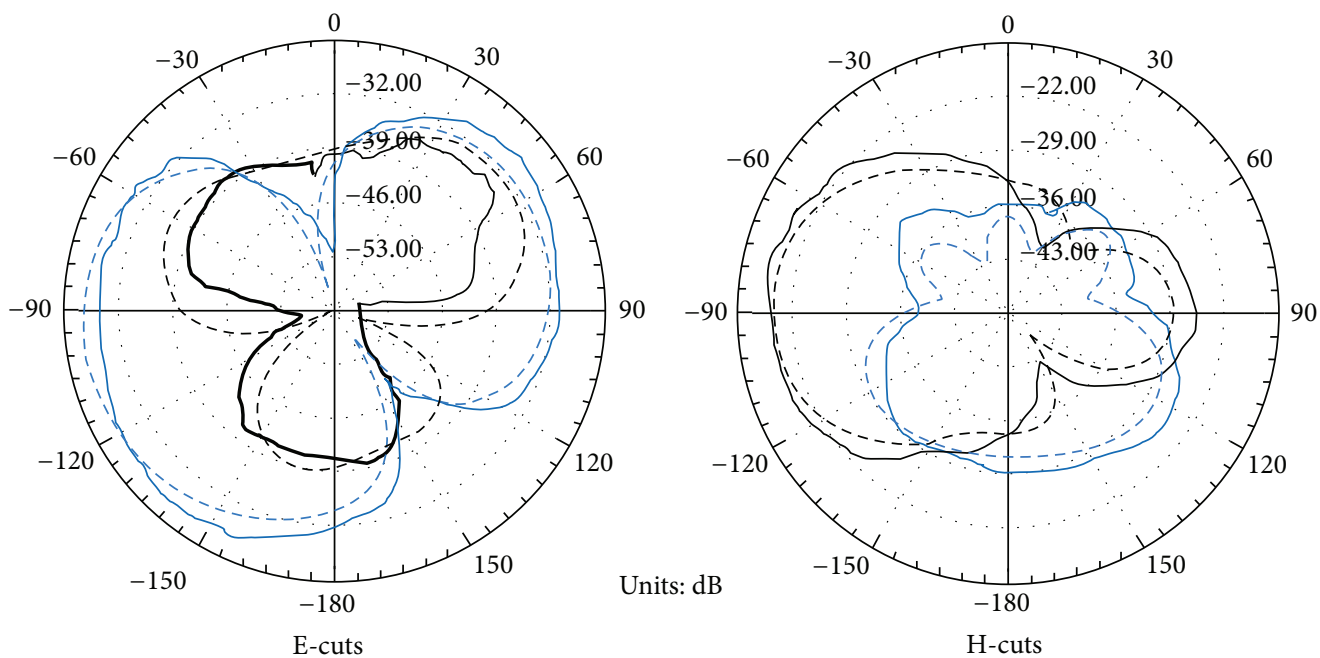

(a)
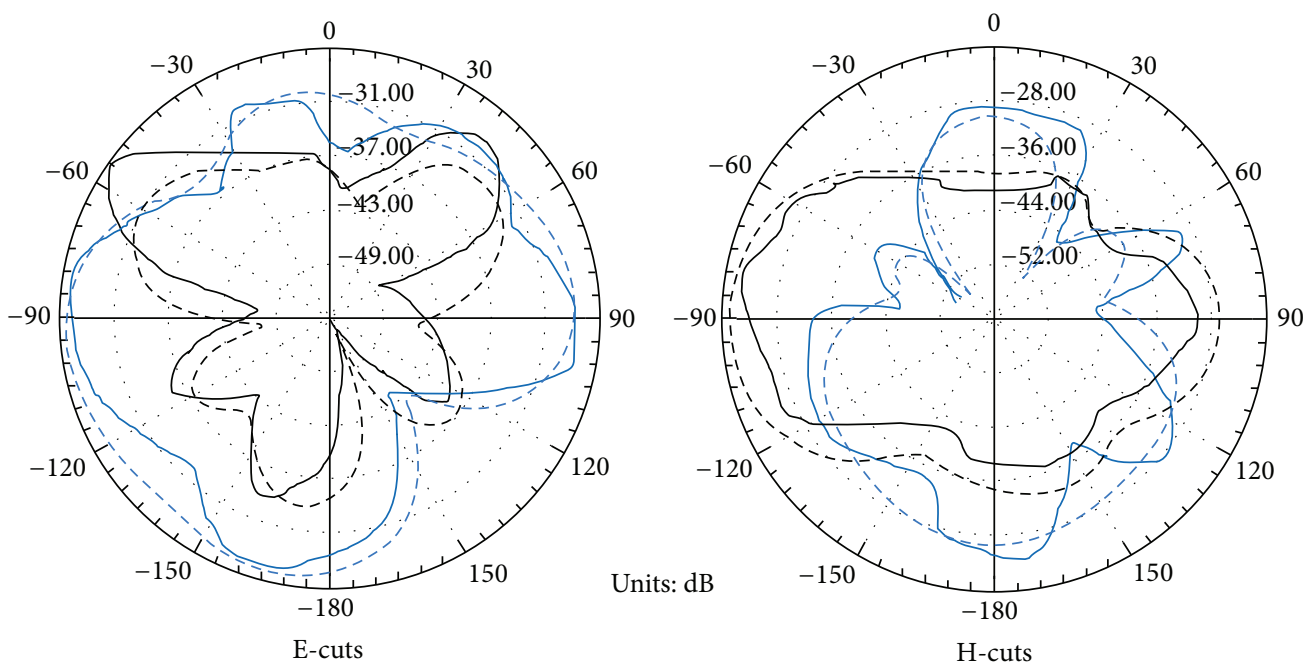

(b)

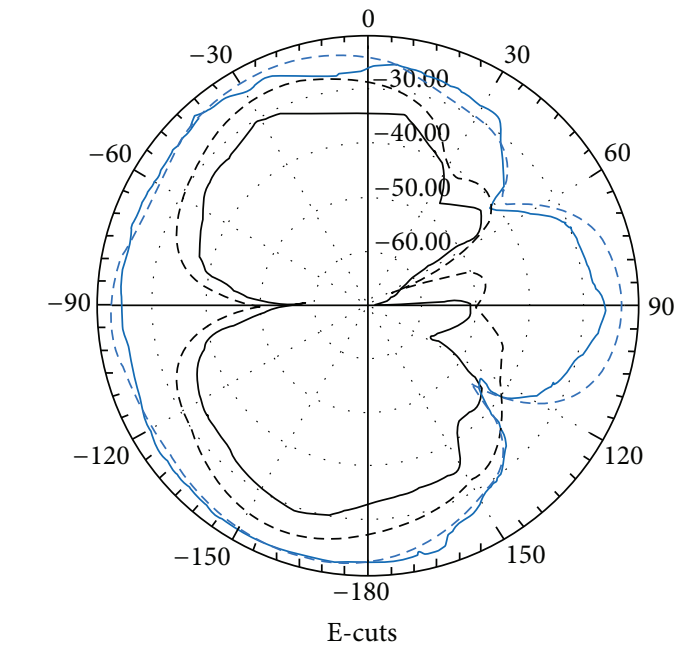

- Measured copolarization — Measured cross-polarization - - Simulated copolarization --- Simulated cross-polarization

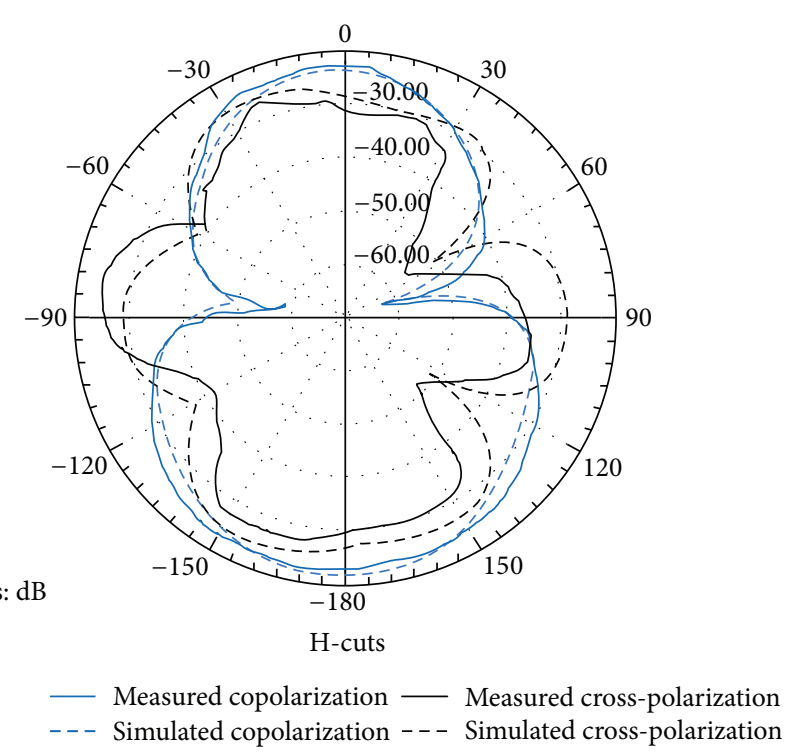

(c)

Figure 7: Measured and simulated co- and cross-polarizations for E- and H-cuts of the proposed antenna at frequencies of (a) 2.4, (b) 3.5, and (c) $5.5 \mathrm{GHz}$. 


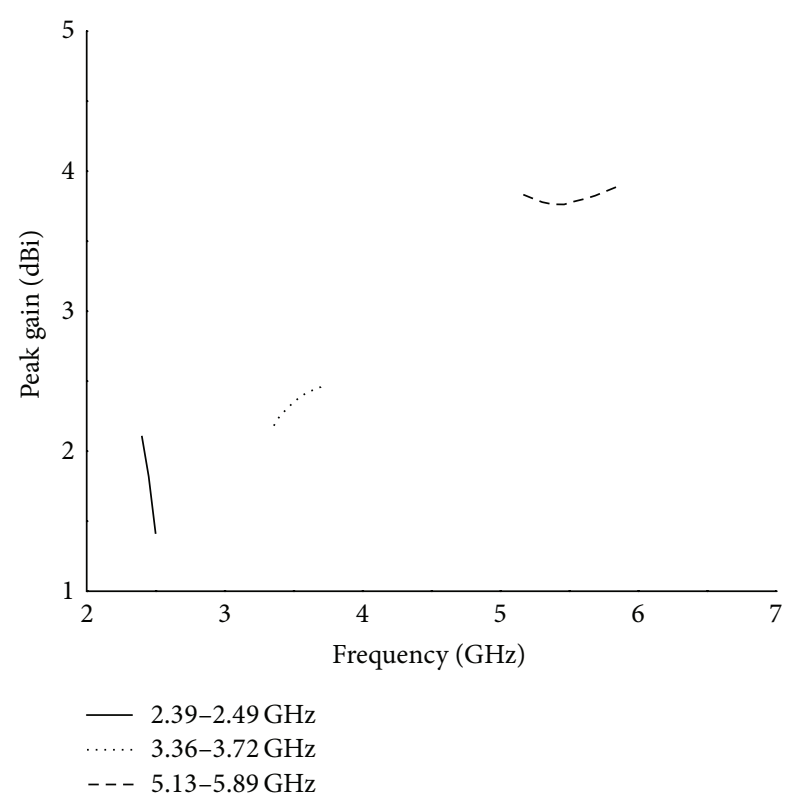

FIGURE 8: Measured peak gains of the proposed triband antenna.

where $c(\mathrm{~m} / \mathrm{s})$ is the speed of light in free space, $f(\mathrm{~Hz})$ is the required resonant frequency, $l$ is the total length of each resonant element, and $\varepsilon_{\text {eff }}$ is the effective relative permittivity. By regulating the geometry parameters of these three resonant elements based on (1), the design can be obtained by numerical simulations. The measurement works are implemented by an Agilent N5244A network analyzer. Good agreement between the simulated results and measured ones can be observed as shown in Figure 4.

\section{Results and Discussion}

In order to further discuss the performance of the presented antenna, the simulated surface current distributions of the antenna at frequencies of $2.4,3.5$, and $5.5 \mathrm{GHz}$ are shown in Figure 5. From this plot, one can clearly observe that most of the surface current is distributed on the inverted L-strip and left side of the asymmetric ring resonator at $2.4 \mathrm{GHz}$, whereas the surface current distributions become more concentrated on the right side of the asymmetric ring resonator and the straight strip at 3.5 and $5.5 \mathrm{GHz}$, respectively.

The triband antenna is influenced by different parameters as shown in Figure 6. Figure 6(a) depicts the simulated reflection coefficients of the antenna when the size of $l_{1}$ (shown in Figure 3(a)) changes. From Figure 6(a), it is clear that the resonant frequency at about $2.4 \mathrm{GHz}$ decreases gradually with the increase of $l_{1}$. As shown in Figures 6(b) and 6(c), the resonant frequencies at about 3.5 and $5.5 \mathrm{GHz}$ are affected by $l_{2}$ and $l_{3}$, respectively. The simulated reflection coefficients of the antenna with varied $l_{4}$ are plotted in Figure 6(d). It can be seen that center frequencies of the three bands are almost unchanged, and the first band of the proposed triband antenna is unaffected by $l_{4}$. In addition, bandwidth of the second band increases with the increase of $l_{4}$, and bandwidth of the third band decreases when $l_{4}$ increases. So, the desired resonant frequencies of the triband antenna can be achieved by changing the values of $l_{1}, l_{2}$, and $l_{3}$.

The simulated and measured far field radiation patterns of co- and cross-polarizations for $\mathrm{E}$ - and $\mathrm{H}$-cuts of the proposed antenna at 2.4/3.5/5.5 GHz are illustrated in Figures 7(a), 7(b), and 7 (c), respectively. The peak gains in all the operating bands are plotted in Figure 8 which reveals that the average peak gains of the three bands are $1.78,2.35$, and $3.82 \mathrm{dBi}$, respectively.

Table 1 gives a comparison between the proposed triband antenna and some previous works. It can be observed that the proposed work realizes triband performance capable of WLAN and WiMAX applications on a low-cost substrate with a compact circuit size as well as wide impedance bandwidths.

\section{Conclusion}

In this paper, a CPW-fed triband antenna for WLAN/ WiMAX communication systems is proposed. The proposed triband antenna consists of an asymmetric ring, an inverted L-strip, and a straight strip. According to the sizes of these three elements, three distinct bands can be obtained, respectively. Compared to antennas proposed in [1-15], the presented antenna has a simple structure with a compact size of only $22 \times 20 \times 1.6 \mathrm{~mm}^{3}$. Measured results demonstrate that the proposed antenna covers the WLAN $(2.4 / 5.2 / 5.8 \mathrm{GHz})$ and WiMAX $(3.5 / 5.5 \mathrm{GHz})$ bands and the antenna has reasonable gains. All these merits indicate that the triband antenna is quite suitable for WLAN and WiMAX applications.

\section{Conflict of Interests}

The authors declare that there is no conflict of interests regarding the publication of this paper.

\section{References}

[1] C.-Y. Pan, T.-S. Horng, W.-S. Chen, and C.-H. Huang, "Dual wideband printed monopole antenna for WLAN/WiMAX applications," IEEE Antennas and Wireless Propagation Letters, vol. 6, pp. 149-151, 2007.

[2] X. L. Sun, L. Liu, S. W. Cheung, and T. I. Yuk, "Dual-band antenna with compact radiator for $2.4 / 5.2 / 5.8 \mathrm{GHz}$ WLAN applications," IEEE Transactions on Antennas and Propagation, vol. 60, no. 12, pp. 5924-5931, 2012.

[3] S.-H. Yeh and K.-L. Wong, "Dual-band F-shaped monopole antenna for 2.4/5.2 GHz WLAN application," in Proceedings of the IEEE Antennas and Propagation Society International Symposium, vol. 4, pp. 72-75, San Antonio, Tex, USA, June 2002.

[4] T. H. Kim and D. C. Park, "CPW-fed compact monopole antenna for dual-band WLAN applications," Electronics Letters, vol. 41, no. 6, pp. 291-293, 2005.

[5] T. W. Koo, D. Kim, J. I. Ryu, J. C. Kim, and J.-G. Yook, "A coupled dual-U-shaped monopole antenna for WiMAX tripleband operation," Microwave and Optical Technology Letters, vol. 53, no. 4, pp. 745-748, 2011. 
[6] X.-J. Liao, H.-C. Yang, N. Han, and Y. Li, "Aperture UWB antenna with triple band-notched characteristics," Electronics Letters, vol. 47, no. 2, pp. 77-79, 2011.

[7] H. H. Li, X. Q. Mou, Z. Ji, H. Yu, Y. Li, and L. Jiang, "Miniature RFID tri-band CPW-fed antenna optimised using ISPO algorithm," Electronics Letters, vol. 47, no. 3, pp. 161-162, 2011.

[8] C.-C. Lin, C.-Y. Huang, and G.-H. Chen, "Obtuse pie-shaped quasi-self-complementary antenna for WLAN applications," IEEE Antennas and Wireless Propagation Letters, vol. 12, pp. 353355, 2013.

[9] P. Xu, Z.-H. Yan, and C. Wang, "Multi-band modified forkshaped monopole antenna with dual L-shaped parasitic plane," Electronics Letters, vol. 47, no. 6, pp. 364-365, 2011.

[10] S. S. Huang, J. Li, and J. Z. Zhao, "Design of a compact triple-band monopole planar antenna for WLAN/WiMAX applications," Progress in Electromagnetics Research C, vol. 48, pp. 29-35, 2014.

[11] S. S. Huang, J. Li, and J. Z. Zhao, "Compact CPW-fed triband antenna for WLAN/WIMAX applications," Progress in Electromagnetics Research C, vol. 49, pp. 39-45, 2014.

[12] Q. Zhao, S. X. Gong, W. Jiang, B. Yang, and J. Xie, "Compact wide-slot tri-band antenna for WLAN/WiMAX applications," Progress in Electromagnetics Research Letters, vol. 18, pp. 9-18, 2010.

[13] J.-H. Yoon, Y.-C. Rhee, and W.-S. Kim, "A rectangular ring, open-ended monopole antenna with two symmetric strips for WLAN and WiMAX applications," International Journal of Antennas and Propagation, vol. 2013, Article ID 109450, 9 pages, 2013.

[14] M. Samsuzzaman, T. Islam, N. H. Abd Rahman, M. R. I. Faruque, and J. S. Mandeep, "Compact modified swastika shape patch antenna for WLAN/WiMAX applications," International Journal of Antennas and Propagation, vol. 2014, Article ID 825697, 8 pages, 2014.

[15] S. T. Fan, Y. Z. Yin, H. Li, S. J. Wei, X. H. Li, and L. Kang, "A novel tri-band printed monopole antenna with an etched $\cap$ shaped slot and a para-sitic ring resonator for wlan and wimax applications," Progress In Electromagnetics Research Letters, vol. 16, pp. 61-68, 2010. 

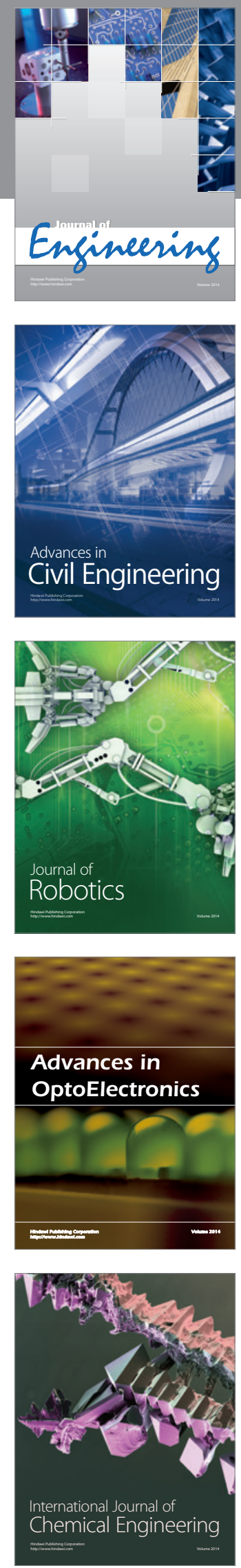

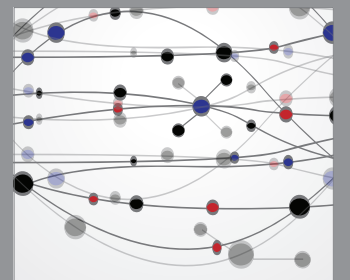

The Scientific World Journal
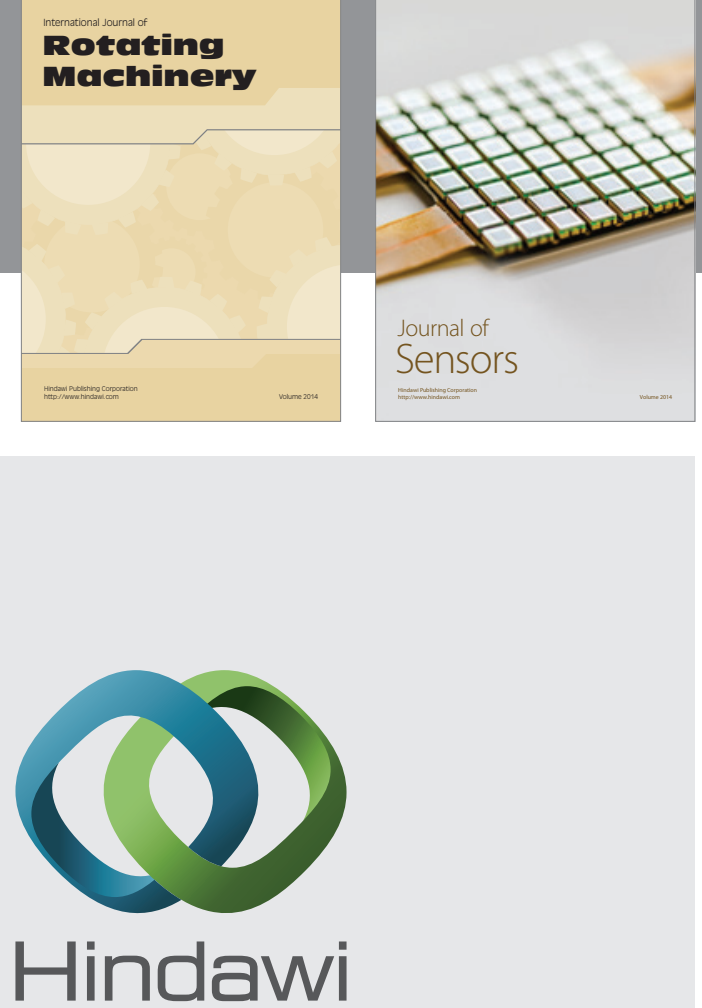

Submit your manuscripts at http://www.hindawi.com
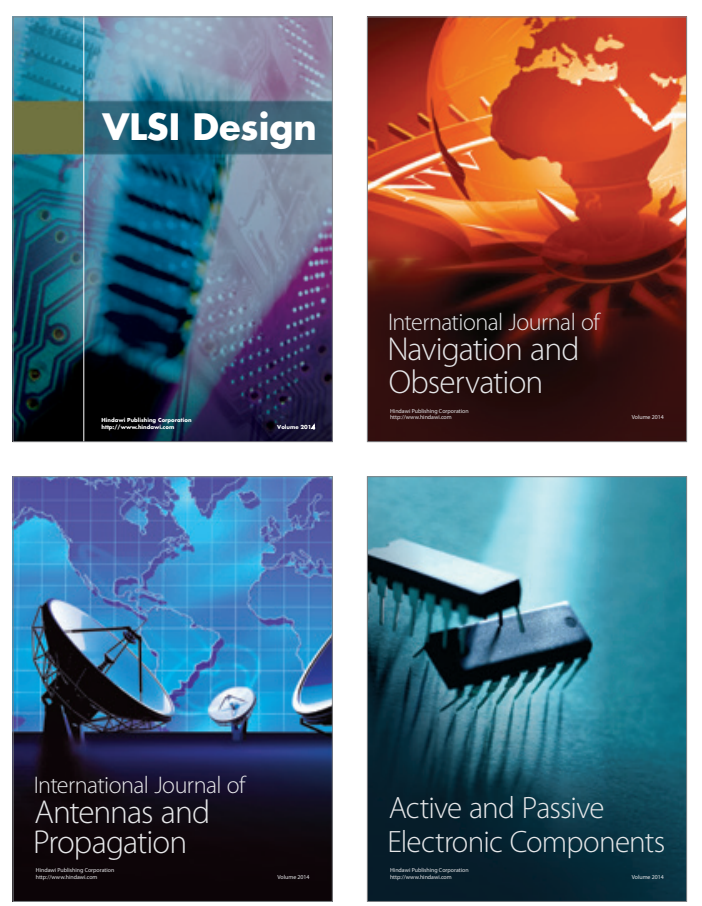
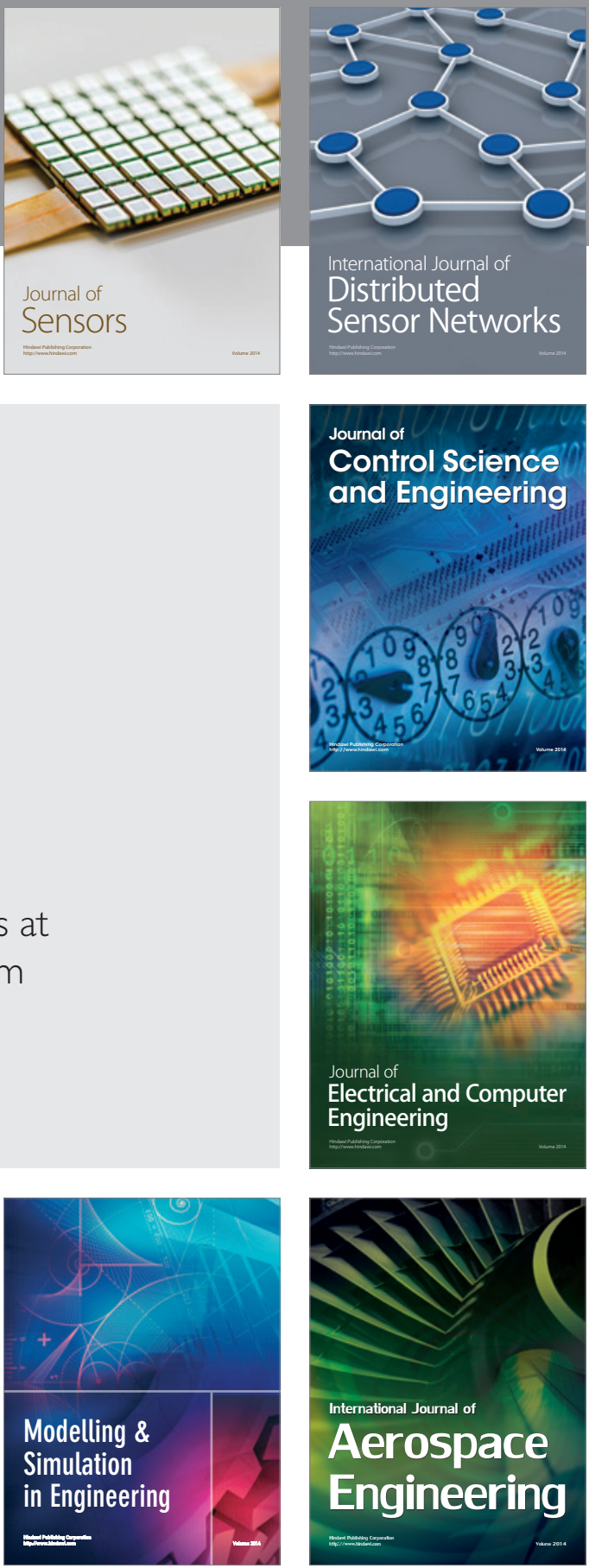

Journal of

Control Science

and Engineering
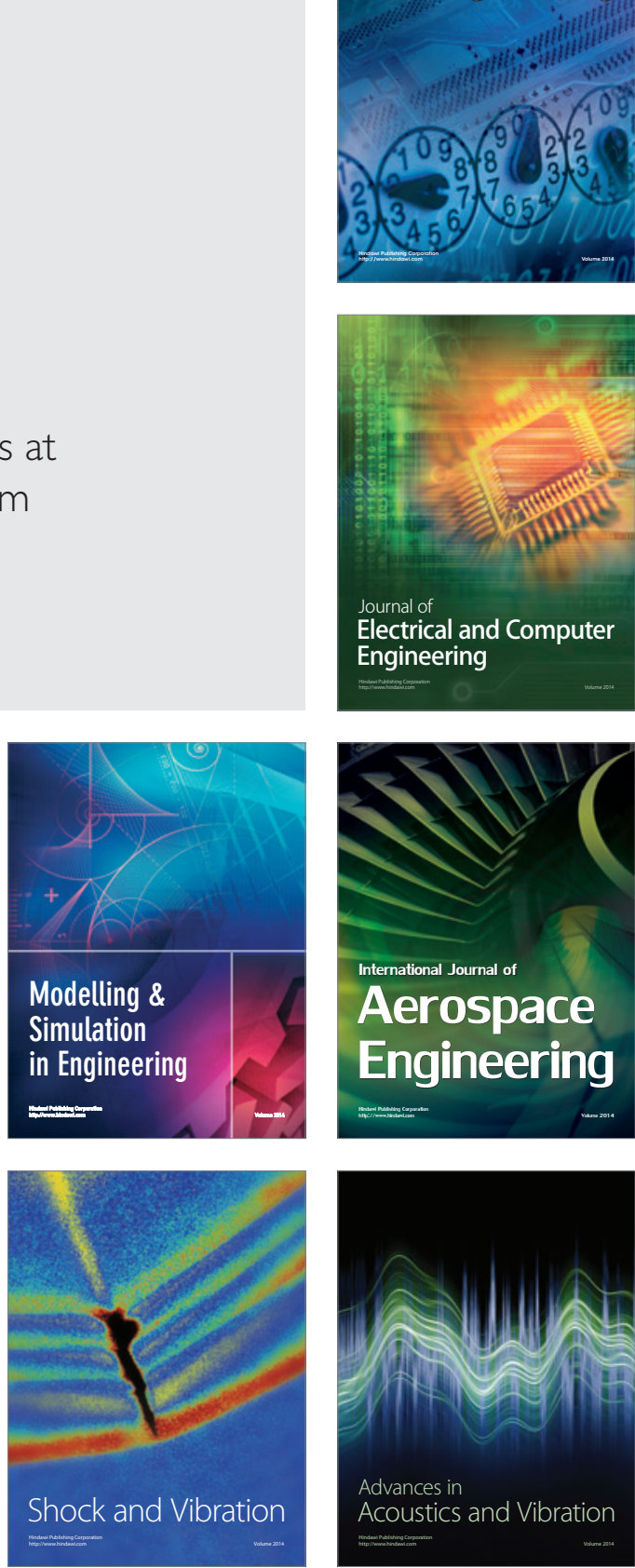